\title{
DIGITAL TRANSFORMATION: CONCEPTUAL FRAMEWORK
}

\author{
Natalja VERINA, Jelena TITKO (D* \\ Ekonomikas un kulturas augstskola, Lomonosova Str. 1/5, LV1019, Riga, Latvia \\ *E-mail: jelena.titko@eka.edu.lv
}

\begin{abstract}
Purpose - the main goal of the current research was to provide a deep understanding of the concept of digital transformation, specifying its key elements/components/categories.

Research methodology - an analysis of the textual information was performed, applying various techniques in the framework of the content analysis. Information database included 30 definitions of the term "digital transformation" and the related terms proposed by academicians and organizations.
\end{abstract}

Findings - the analysis of the text segments of the investigated concept yielded three categories of digital transformation in business; 1) technologies, 2) processes and management, 3) people. Based on the research results, the conceptual model of digital transformation was created.

Research limitations - the research was limited by the number of the analyzed definitions, as well as by the variety of methods applied.

Practical implications - the research instrument for a survey among business sector representatives can be developed using the findings of the given study, in particular, for structuring the questionnaire's blocks.

Originality/Value - the current research provides a platform for further empirical investigation of the level of a company's digital transformation.

Keywords: digital transformation, digitalization, concept, content analysis.

JEL Classification: M10, O33.

Conference topic: Digitalization of Business Processes: Trends, Challenges, Solutions.

\section{Introduction}

Digital transformation (DT) and its components, drivers and barriers for DT in business, its strategies and its impact on companies operating efficiency - all these topics are frequently debated during the last two decades. It is one of the policy areas of the European Commission and the Organisation for Economic Co-operation and Development.

The current research is devoted to the investigation of the concept of digital transformation in business. Considering different digital transformation perceptions, there is quite a wide range of studies focusing on different questions related to the digital transformation barriers, strategies, elements, etc. It predetermines different approaches to the definition of the concept itself, even within the business field. The main goal was to provide a deep understanding of the concept of digital transformation, specifying its key elements/components/categories.

The general research questions are:

1. What are the core elements of digital transformation?

2. What are the factors driving the process of digital transformation in business?

To achieve the research goal, the authors analysed concept-related text segments and definitions of the term "digital transformation" proposed by individual researchers, governmental authorities and business experts, extracted from the scientific databases Google Scholar and EBSCO, reports and surveys by the European Commission, OECD, World Economic Forum and other authorities, as well as papers published by non-governmental organizations.

The analysis was performed, applying the procedure of the frequency analysis within the content analysis method and evaluating the inter-rater reliability with Cohen's Kappa coefficient. Besides, the expert survey was used to increase the reliability of the previously received results, and to evaluate the factors affecting the success of digital transformation processes in business. Hamlet II and SPSS software were used for data processing. 
The current research contributes to the body of knowledge related to digital transformation processes and provides a platform to further studies in this area. It is a starting point for research series in the field of business digital transformation that aims, in particular, to investigate the issues regarding staff resistance to digital transformation processes. One of the areas for future studies will be a higher education sector.

\section{The concept of digital transformation}

Nowadays, digital transformation is a buzzword in an academic and business environment. Business, education, banking, government, manufacturing - almost every industry is being "digitally transformed" in the period of the fourth industrial revolution.

Elements of digital transformation, drivers and barriers, value creation through digital transformation - these and other related topics are frequently discussed in an academic environment last 20-25 years (Shallmo, Williams, \& Boardman, 2017; Matt, Hess \& Benlian, 2015; Ismail, Khater, \& Zaki, 2017). Call for digital transformation in Google Scholar data basis yielded three million results. The request for the key words "digital transformation" in Web of Science and SCOPUS bases also resulted in plenty of scientific papers, the amount of which is increasing every year (see Figure 1).

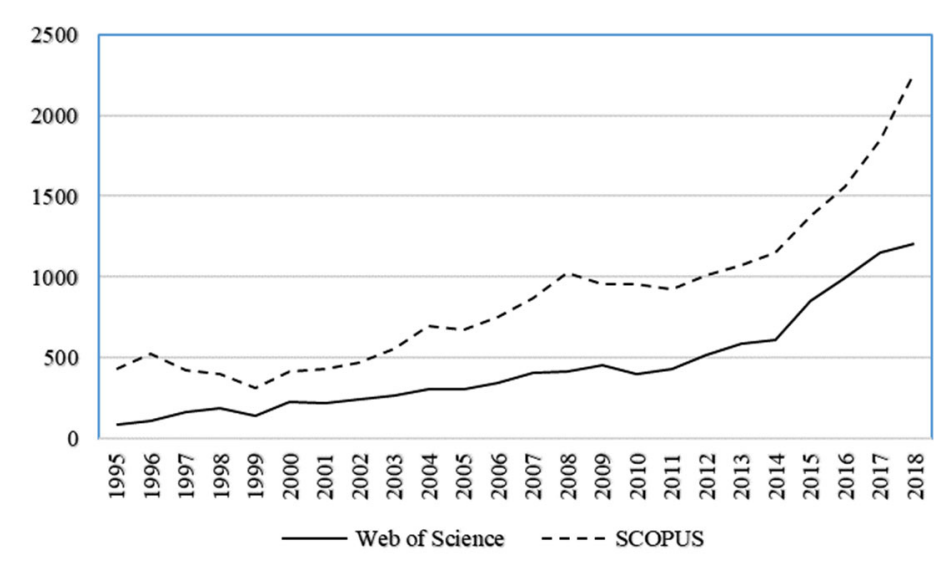

Figure 1. Number of publications devoted to Digital transformation: results from Web of Science and SCOPUS scientific databases 1995-2018 (source: authors' compilation)

The European Commission (EU) also prioritizes digital transformation of business and society. Digital Transformation Monitor and Digital Transformation Scoreboard are among EU initiatives aimed to measure progress on digital transformation in EU countries (European Commission, 2019).

In 2017, the Organisation of Economic Cooperation and Development (OECD) launched a new global project "Going Digital: Making the Transformation Work for Growth and Well-being". Its goal is "to help policymakers better understand the digital transformation that is taking place and create a policy environment that enables their economies and societies to prosper in a world that is increasingly digital and data-driven" (OECD, 2018).

Why so much attention is paid to digital transformation? First, digitalization is an integral part of the overwhelming development of society, economics and business. Digitalization and globalization - or vice versa - these processes determine our existence nowadays. According to the European Commission forecasts, a "transformative industrial and technological revolution" will be one of the key global trends to 2030. "All aspects of society - such as politics, governance, education, science, lifestyles, collective intelligence networks, the setting-up of open systems, and health, including the transformation of the human genome - will be transformed by technological breakthroughs" (ESPAS, 2015).

There are plenty of definitions provided by academicians, government authorities and business experts. Some of them are summarized in Table 1.

The digital transformation of a company requires a fundamental organizational change. Based on experts from Bostom Consulting Group, "a digital transformation requires instilling a culture that supports the change while enabling the company's overarching strategy" (Hemerling, Kilmann, Danoesastro, Liza Stutts, \& Ahern, 2018). The singular focus should on customers and their needs (Schwertner, 2017; Dahlstrom, Erikson, Khanna, \& Meffert, 2017). Citing Bloomberg (2018), "digitization and digitalization are essentially about technology, but the digital transformation is not. Digital transformation is about the customer". The processes of the organizational change and incorporating of a digital culture should be initiated and supported by executives (Gillin, 2016; Schwertner, 2017; Hemerling et al., 2018).

Human element (within and outside the organization being digitally transformed or initiating this process) is not very much focused. However, some researchers point out that successful digital transformation requires "motivated employee involvement" (Schwertner, 2017) and that the human factor is more important than the technology itself 
(Del Rowe, 2017). People-driven approach to DT is emphasizing also in OECD's (2018) Ministerial report on Inclusive Growth: "If we lose sight of the individual and the need for all individuals to be engaged and benefit from the digital transformation, the transformation cannot be positive and inclusive".

Table 1. Definitions of the term "digital transformation" (source: authors' compilation)

\begin{tabular}{|c|l|}
\hline Source & \multicolumn{1}{c|}{ Definition } \\
\hline $\begin{array}{c}\text { European Commission } \\
\text { (2019) }\end{array}$ & $\begin{array}{l}\text { "Digital transformation is characterized by a fusion of advanced technologies and the integration } \\
\text { of physical and digital systems, the predominance of innovative business models and new pro- } \\
\text { cesses, and the creation of smart products and services." } \\
\text { "Digital transformation refers to the economic and societal effects of digitization and } \\
\text { digitalization. Digitization is the conversion of analog data and processes into a machine-readable } \\
\text { format. Digitalization is the use of digital technologies and data as well as their interconnection } \\
\text { which results in new or changes to existing activities." }\end{array}$ \\
\hline Ismail, Khater, and Zaki \\
(2017) & $\begin{array}{l}\text { [Digital transformation is a] "process through which companies converge multiple new digital } \\
\text { technologies, enhanced with ubiquitous connectivity, with the intention of reaching superior per- } \\
\text { formance and sustained competitive advantage, by transforming multiple business dimensions, } \\
\text { including the business model, the customer experience (comprising digitally enabled products } \\
\text { and services) and operations (comprising processes and decision-making), and simultaneously } \\
\text { impacting people (including skills talent and culture) and networks (including the entire value } \\
\text { svstem)" }\end{array}$ \\
\hline Schwertner (2017) & $\begin{array}{l}\text { "the application of technology to build new business models, processes, software and systems that } \\
\text { result in more profitable revenue, greater competitive advantage, and higher efficiency." }\end{array}$ \\
\hline Deloitte (2018) & $\begin{array}{l}\text { "Digital transformation is the use of technology to radically improve the performance or reach of } \\
\text { an organization. In a digitally transformed business, digital technologies enable improved pro- } \\
\text { cesses, engaged talent, and new business models." }\end{array}$ \\
\hline Bloomberg (2018) & $\begin{array}{l}\text { "Digital transformation requires the organization to deal better with change overall, essentially } \\
\text { making change a core competency as the enterprise becomes customer-driven end-to-end. Such } \\
\text { agility will facilitate ongoing digitalization initiatives but should not be confused with them." }\end{array}$ \\
\hline
\end{tabular}

Literature review to investigate the concept of digital transformation was done by various researchers (Nwaiwu, 2018; Reis, Amorim, Melão, \& Matos, 2018; Morakanyane, Grace, \& O’Reilly, 2017; Hausberg et al., 2018; Henriette, Feki, \& Boughzala, 2015). The main points differing the current research from the previous ones are that the authors used most recent publications for data collection, and also that the concept was viewed from the business sectors representatives, who were engaged in the process of DT implementation.

\section{Research methodology}

The current research was divided into several stages:

1. Data collection.

2. The initial content analysis aimed to reveal elements and categories within the concept.

3. Data analysis based on pre-determined elements, using the method of frequency analysis.

4. Data analysis based on pre-determined categories, using inter-rater reliability evaluation technique.

5. Expert survey to increase the reliability of results.

During the $1^{\text {st }}$ stage of the research, the authors collected definitions of the term "digital transformation", using scientific databases Google Scholar and EBSCO, reports, and surveys by the European Commission, OECD, World Economic Forum and other authorities, as well as papers published by non-governmental organizations. As a result, 30 definitions and text segments collected. Data set divided into three content blocks according to the information source:

1. Definitions of Digital Transformation, which are used by national and international political and economic authorities, for instance, European Commission, 2019; OECD, 2018; World Economic Forum, 2016, 2018a, 2018b, 2018c);

2. Definitions of digital transformation, which are used by non-governmental organizations (NGO), business practitioners and research institutions (Petersen, 2018; Bloomberg, 2018; Corver \& Elkhuizen, 2014; MIT Centre for Digital Business and Capgemini Consulting, 2011; Digital transformation: online guide, 2018; Gillin, 2016; Next-gen IT, 2018; Kanaracus, Sato, \& Wang, 2017; Terrar, 2015; Wang, 2015; Westerman \& Bonnet, 2015; Zysman et al., 2011; "What is digital transformation?”, 2015);

3. Definitions of digital transformation, which are used by researchers (Berman, 2012; Cherry, 2015; Del Rowe, 2017; Fitzgerald, Kruschwitz, Bonnet, \& Welch, 2014; Horlacher \& Hess, 2016; Iansiti \& Lakhani, 2014; 
Kane, Palmer, Phillips, Kiron, D., \& Buckley, 2015; King, 2013; McDonald \& Rowsell-Jones, 2012; Matt, Hess, \& Benlian, 2015; Schwertner, 2017; von Knop, 2016; Zhu, Kraemer, \& Xu, 2006).

The following structuring of the definitions is used to show the diversity of the information sources but has not been used for data processing.

The initial content analysis was performed by using a simplified tool - TagCrowd (a web application for visualizing word frequencies in any text by creating a word cloud). It allowed creating a list of codes (labels for a group of synonyms) for further processing. Then, a procedure of the frequency analysis with the application of HAMLET II software was performed.

To assess inter-rater reliability when coding qualitative data (definitions), Cohen's Kappa coefficient (Cohen, 1960) was measured. The algorithm of the calculation of the coefficient is described in details by Wood (2007). The critical value for the coefficient is 0.7 , the lower value considered to be unsatisfactory, and the procedure should be iterated after mutual discussion.

Expert were surveyed, using the authors' developed questionnaire that contained a respondent profile section, as well as two main parts: 1) a list of DT definitions that were offered to the respondents for evaluation, using 5-point scale to express their (dis)agreement; 2) the list of activities/factors to assess their significance for successful DT implementation. Ten experts participated in the survey: representatives of higher education institutions with a strategy towards digitalization, heads of IT departments from business sector, heads of HR departments surveyed with the assistance of SmartHR (Latvian HR representatives' community), representative of academia, and a representative of BeSmart (multimedia communication platform on business technologies). Nine experts are engaged in DT processes at the strategic level.

\section{Research results}

Initial content analysis with the application of TagCrowd web instrument yielded a list of elements, which were grouped by the authors and the groups were labeled to create a vocabulary list (Figure 2). Vocabulary list was required by HAMPLET II software to perform further analysis. It contains main entries (codes) and list of synonyms.

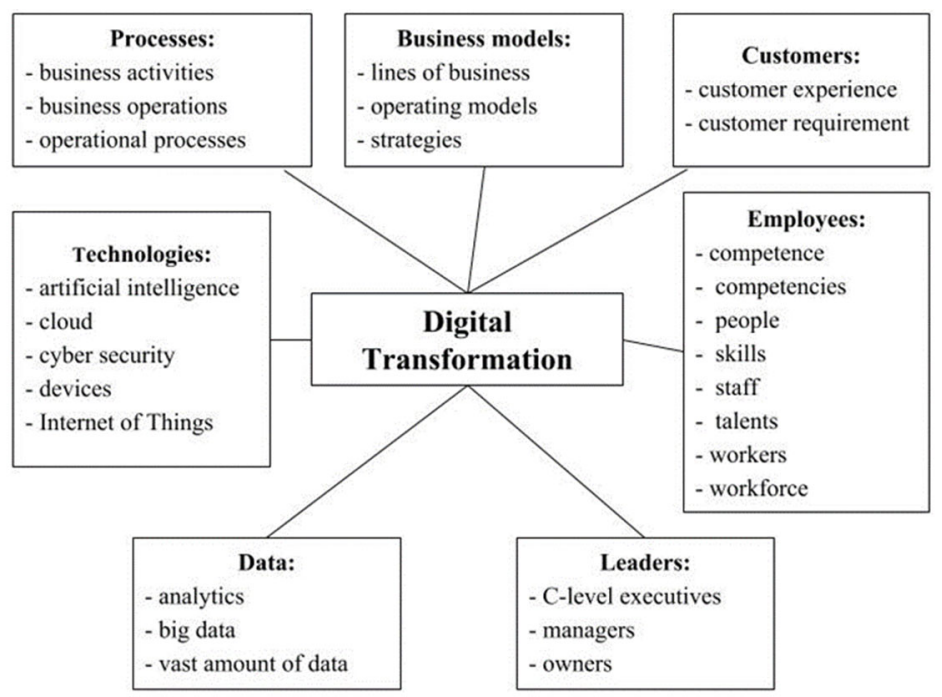

Figure 2. Vocabulary list for Hamlet (source: authors' development)

The results of the analysis performed in Hamlet are reflected in a frequency table (see Figure 3).

$\begin{array}{lclll}\text { VOC.LST. } & \text { FREQUENCY \% } & \text { VOC.LST. \% } & \text { TEXT } & \text { CONTEXT UNITS } \\ \text { Business models } & 10 & 11.63 & 0.55 & 8 \\ \text { Customers } & 5 & 5.81 & 0.27 & 3 \\ \text { Data } & 12 & 13.95 & 0.66 & 10 \\ \text { Employees } & 7 & 8.14 & 0.38 & 6 \\ \text { Leaders } & 2 & 2.33 & 0.11 & 2 \\ \text { Processes } & 13 & 15.12 & 0.71 & 10 \\ \text { Technologies } & 37 & 43.02 & 2.03 & 21\end{array}$

Figure 3. Vocabulary list statistics (source: authors' development) 
Predictably, technologies are the most frequently mentioned element regarding the concept of digital transformation. Less, but also often emphasized elements are "Processes", "Data" and "Business models". The authors' latent purpose was to find arguments about the importance of the "people" element. Based on the preliminary content analysis, we cannot state that it is the most significant element of DT that researchers are focusing on. On the other hand, the list of definitions was not so large to make any unambiguous conclusions. Citing the senior director and head of digital commerce platform transformation at Dell EMC, big changes towards digital transformation "are not solved by technology, but by people. People, process and technology need to be aligned" (Petersen, 2018).

In the next stage of the research, the authors, using another set of categories, worked independently on the analysis of the collected definitions. These categories were selected, based on the citation of a senior director and head of digital commerce platform transformation at Dell EMC Sarika Puri. Speaking about the successful business DT, he stated that "people, process and technology need to be aligned". The analysis was made, using the pre-determined categories, which emerged in the result of the grouping of the identified DT concept elements (Table 2). The following categories and codes were used for coding:

1. Technologies (TECH - code 1$)$;

2. Management /Processes (MANAGE - code 2);

3. People (PEOPLE - code 3).

Table 2. Categories of the concept "Digital transformation" and the elements within (source: authors' development)

\begin{tabular}{|l|l|l|}
\hline \multicolumn{1}{|c|}{ Technologies } & \multicolumn{1}{c|}{ Management / Processes } & \multicolumn{1}{c|}{ People } \\
\hline - Data & & - Customers \\
- Big data & - Business models & - Employees / workforce / people \\
- Cloud & - Operating models & - Managers \\
- Mobile devices & - Operational processes & - Executives \\
- Social media & - Strategies & - Talents \\
- Software & - Business activities & - Owners \\
- Analytics & - Organizational structure & - Suppliers \\
- Embedded devices & - Organizational culture & - Partners \\
- Artificial intelligence & - Coordination mechanism & - Stakeholders \\
- The Internet of Things & - Products & - Competencies \\
- Cybersecurity & - New services & \\
- App marketplaces & & \\
\hline
\end{tabular}

For measuring the agreement between the authors on categories assigned to the definitions, Cohen's Kappa coefficient was calculated in SPSS. The first attempt yielded the coefficient's value equal to 0.412 .

Due to the unsatisfactory level of the agreement, the content of the definitions was discussed by the raters and the coding procedure was iterated. The second attempt yielded the coefficient's value equal to 0.831 (see Figure 4).

Raterl * Rater2 Crosstabulation.

\begin{tabular}{|rr|r|r|r|r|}
\hline & & \multicolumn{3}{|c|}{ VAR00002 } & \multirow{2}{*}{ Total } \\
\cline { 3 - 5 } & 1,00 & 1,00 & 2,00 & 3,00 & \\
\hline \multirow{3}{*}{ VAR00001 } & 2,00 & 8 & 1 & 0 & 9 \\
& 3,00 & 0 & 15 & 1 & 16 \\
Total & & 0 & 1 & 4 & 5 \\
\hline
\end{tabular}

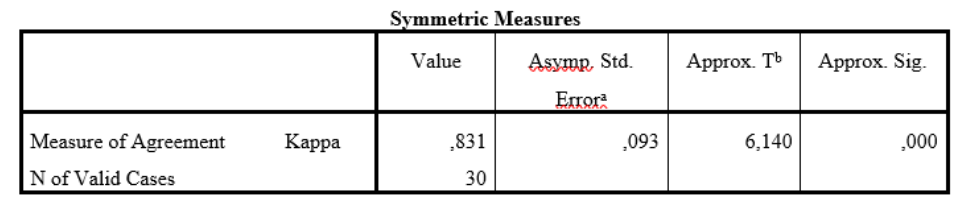

Figure 4. Cohen's Kappa calculation in SPSS II (source: authors' development)

At the satisfactory rate of agreement on categories assigned to the collected definitions, the category "MANAGE" was recognized as the most significant category among three pre-determined categories. Definitions of DT concept usually contain a resulting effect from DT processes that, in turn, is expressed in improved processes, new business models, etc. 
To visualize the research results, the simplified conceptual model of digital transformation was created by the authors, focusing attention on factors enabling DT processes, as well as on potential outcomes for business and society, (see Figure 5).

\begin{tabular}{|c|c|c|}
\hline DRIVERS & & RESULTS \\
\hline $\begin{array}{c}\text {-emergence of new markets and new } \\
\text { business opportunities } \\
\text { development of e-business } \\
\text {-increased competition } \\
\text {-customer requirements and increased needs } \\
\text { progress in technologies } \\
\text { digitization of tasks and processes } \\
\text {-increased cooperation between old-timers } \\
\text { and digital natives } \\
\text {-executive support } \\
\text { recognition of the role of digital } \\
\text { technologies among leaders }\end{array}$ & $\begin{array}{l}\text { TECHNOLOGIES } \\
\text { MANAGEMENT } \\
\text { PEOPLE }\end{array}$ & $\begin{array}{c}\text { 'boost sustainable growth } \\
\text {-enhance well-being } \\
\text {-more effective knowledge collection, sharing and use } \\
\text {-access to global markets } \\
\text {-improve market intelligence } \\
\text {-sustained protection against digital disruption } \\
\text { - faster and more successful innovation } \\
\text { 'create value for business } \\
\text {-improved efficiency and reduced costs } \\
\text { creating new revenue models and increased revenues } \\
\text { open new opportunities for complementary investments } \\
\text { 'greater competitive advantage } \\
\text { 'greater customer interaction and collaboration }\end{array}$ \\
\hline
\end{tabular}

Figure 5. A conceptual model of digital transformation (source: authors' development)

The central block of the model presents three main categories of the concept of digital transformation, while side blocks represent "inputs" and "outputs", but specifically the factors driving DT processes and resulting effects of successful digital transformation.

The developed model allows better understanding of the main elements and "surrounding" factors of digital transformation that, in turn, can help in the next steps of our research, for instance, in developing a questionnaire to investigate the awareness about digital transformation about managers and employees in different sectors, as well as to evaluate the perceived importance of DT processes.

Based on the viewpoint of the experts, the most appropriate definitions of business digital transformation are the following:

1. [Business digital transformation is ...] "the application of technology to build new business models, processes, software and systems that result in more profitable revenue, greater competitive advantage, and higher efficiency" (Schwertner, 2017).

2. "Digital transformation is the investment in people and technology to drive a business that is prepared to grow, adapt, scale, and change into the foreseeable future" (Del Rowe, 2017).

In turn, the least accepted definition was "Digital transformation as the integration of digital technology into all areas of a business resulting in fundamental changes to how businesses operate and how they deliver value to customers" ("What is a digital transformation?", 2015).

As for the most important factors for successful business digital transformation, the company's value and human factors were selected by most experts (see Table 3).

Table 3. Perceived importance of factors affecting DT processes (source: authors' conducted survey results)

\begin{tabular}{|c|c|}
\hline $\begin{array}{c}\text { Number of experts evaluated } \\
\text { the certain factor as important }\end{array}$ & \multicolumn{1}{|c|}{ Factor } \\
\hline 9 & $\begin{array}{l}\text { - Company's strategy; orientation towards digital transformation } \\
\text { - Organizational culture; company's values } \\
\text { - Self-motivation of employees; readiness to accept changes }\end{array}$ \\
\hline 8 & - Staff knowledge and competence \\
\hline 7 & - Existing infrastructure (technology) \\
\hline 6 & - Financial (other) motivation system, supporting staff engagement into DT processes \\
\hline 5 & - The financial situation in a company \\
\hline
\end{tabular}


Most experts agreed that digital transformation implementation mainly depends on the corporate message to the company's employees, as well as on employees' willingness to change and their internal resistance or readiness for transformation processes. It means that top-executives should think about corporate values and their proclamation among staff members before starting the process of transformation.

\section{Conclusions}

The aim stated by the authors within the current research was to get an insight into the concept of digital transformation, specifically business DT, focusing especially on the human element.

The analysis resulted in the conceptual model of digital transformation that contains three main blocks: DT drivers, DT categories and DT outcomes.

Answering the research questions, we can state that the main elements of the concept are processes and technologies, but it should be pointed out that digital transformation is not about the implementation of IT solutions only. We should think about it in a broader context as about "organizational change", "cultural transformation" and "moving towards customer-centric approach". In this regard, the element "people" becomes essential, and even more important than anything else does. In addition, one of the main barriers to transformation could be staff resistance. This is our topic for further investigation, and we will start with a higher education sector. Our purpose will be to identify the biggest obstacles for ensuring a qualitative study process aligned with a digitalization strategy.

Focusing on human factor to boost DT processes assumes not only internal communication with staff members and other stimulating activities, such as training and motivating, but also re-building recruitment programme. Based on McKinsey experts (Dahlstrom et al., 2017), "Talent priorities should be based on a clear understanding of the skills needed at all levels of the business. This requires investing in building relevant digital capabilities that fit with the strategy."

\section{Disclosure statement}

The authors do not have any competing financial, professional, or personal interests from other parties.

\section{References}

Berman, S. J. (2012). Digital transformation: opportunities to create new business models. Strategy \& Leadership, 40(2), 16-24. https://doi.org/10.1108/10878571211209314

Bloomberg, J. (2018). Digitization, digitalization, and digital transformation: confuse them at your peril. Retrieved from https://www.forbes.com/sites/jasonbloomberg/2018/04/29/digitization-digitalization-and-digital-transformation-confusethem-at-your-peril/\#2dd1ce842f2c

Cherry, M. A. (2015). Beyond misclassification: The digital transformation of work. Comparative Labor Law \& Policy Journal, 29. Retrieved from https://scholarship.law.slu.edu/cgi/viewcontent.cgi?article=1009\&context=faculty

Cohen, J. (1960). A coefficient of agreement for nominal scales. Educational and Psychological Measurement, 20(1), 37-46. https://doi.org/10.1177/001316446002000104

Corver, Q., \& Elkhuizen, G. (2014). A framework for digital business transformation cognizant. Retrieved from https://www.cognizant.com/InsightsWhitepapers/a-framework-for-digital-business-transformation-codex-1048.pdf

Dahlstrom, P., Erikson, L., Khanna, S., \& Meffert, J. (2017). From disrupted to disruptor: Reinventing your business by transforming the core. Retrieved from https://www.mckinsey.com/ /media/mckinsey/business\%20functions/mckinsey\% 20digital/our\%20insights/digital\%20reinvention/digital\%20reinvention.ashx

Del Rowe, S. (2017). Digital transformation needs to happen: the clock is ticking for companies that have been unwilling to embrace change. CRM Magazine, 2l(10). Retrieved from https://www.destinationcrm.com/Articles/Editorial/MagazineFeatures/Digital-Transformation-Needs-to-Happen-Now-120789.aspx

Deloitte. (2018). Digital enablement turning your transformation into a successful journey. Retrieved from https://www2.deloitte.com/content/dam/Deloitte/ie/Documents/Technology/IE_C_HC_campaign.pdf

Digital transformation: online guide to digital business transformation. (2018). Retrieved from https://www.i-scoop.eu/digitaltransformation/

ESPAS. (2015). Global trends to 2030: Can the EU meet challenges ahead? Retrieved from https://ec.europa.eu/epsc/sites/epsc/ files/espas-report-2015.pdf

European Commission. (2019). Digital transformation. Retrieved from https://ec.europa.eu/growth/industry/policy/digitaltransformation_en

Fitzgerald, M., Kruschwitz, N., Bonnet, D., \& Welch, M. (2014). Embracing digital technology: A new strategic imperative. MIT Sloan Management Review, 55(2). Retrieved from https://sloanreview.mit.edu/projects/embracing-digital-technology/

Gillin, P. (2016). 12 digital transformation strategies from GE, Domino's, Scotiabank. Retrieved from https://www.hpe.com/us/en/insights/articles/12-digital-transformation-strategies-from-ge-dominos-scotiabank-1612.html 
Hausberg, J., Liere-Netheler, K., Packmohr, S., Pakura, S., \& Vogelsang, K. (2018). Digital transformation in business research: a systematic literature review and analysis. In DRUID18. Copenhagen Business School, Copenhagen, Denmark. Retrieved from https://ssrn.com/abstract=3169203

Hemerling, J., Kilmann, J., Danoesastro, M., Liza Stutts, L., \& Ahern, C. (2018). It's not a digital transformation without a digital culture. Retrieved from https://www.bcg.com/publications/2018/not-digital-transformation-without-digital-culture.aspx

Henriette, E., Feki, M., \& Boughzala, I. (2015). The shape of digital transformation: A systematic literature review. MCIS 2015 Proceedings, 431-443.

Horlacher, A., \& Hess, T. (2016). What does a Chief Digital Officer do? Managerial tasks and roles of a new C-level position in the context of digital transformation. In 2016 49th Hawaii International Conference on System Sciences (HICSS) (pp. 51265135). IEEE. https://doi.org/10.1109/HICSS.2016.634

Iansiti, M., \& Lakhani, K. R. (2014). Digital ubiquity: How connections, sensors, and data are revolutionizing business. Harvard Business Review, 92(11), 90-99.

Ismail, M. H., Khater, M., \& Zaki, M. (2017). Digital business transformation and strategy: What do we know so far? Retrieved from https://cambridgeservicealliance.eng.cam.ac.uk/resources/Downloads/Monthly\%20Papers/2017NovPaper_Mariam.pdf

Kanaracus, C., Sato, C., \& Wang, R. R. (2017). Constellation research 2017: digital transformation study. Retrieved from https://www.constellationr.com/research/constellation-research-2017-digital-transformation-study

Kane, G. C., Palmer, D., Phillips, A. N., Kiron, D., \& Buckley, N. (2015). Strategy, not technology, drives digital transformation. MIT Sloan management review and Deloitte University Press. Retrieved from https://sloanreview.mit.edu/projects/strategydrives-digital-transformation/

King, H. (2013). What is digital transformation? The Guardians. Retrieved from: https://www.theguardian.com/medianetwork/media-network-blog/2013/nov/21/digital-transformation

Matt, C., Hess, T., \& Benlian, A. (2015). Digital transformation strategies. Business and Information Systems Engineering, 57(5), 339-343. https://doi.org/10.1007/s12599-015-0401-5

McDonald, M. P., \& Rowsell-Jones, A. (2012). The digital edge: exploiting information \& technology for business advantage. Stamford: Gartner, Inc.

MIT Centre for Digital Business and Capgemini Consulting. (2011). Digital transformation: a roadmap for billion-dollar organization. Retrieved from https://www.capgemini.com/wp-content/uploads/2017/07/Digital_Transformation_A_RoadMap_for_Billion-Dollar_Organizations.pdf

Morakanyane, R., Grace, A. A., \& O'Reilly, P. (2017). Conceptualizing digital transformation in business organizations: a systematic review of literature. In 30th Bled conference: digital transformation - from connecting things to transforming our lives. Maribor: Maribor Press. https://doi.org/10.18690/978-961-286-043-1.30

Next-gen IT infrastructure strategy to guide digital transformation. (2018). Retrieved from https://searchcio. techtarget.com/definition/digital-transformation

Nwaiwu, F. (2018). Review and comparison of conceptual frameworks on digital business transformation. Journal of Competitiveness, 10(3), 86-100. https://doi.org/10.7441/joc.2018.03.06

OECD. (2018). Going digital in a multilateral world. Retrieved from https://www.oecd.org/going-digital/C-MIN-2018-6-EN.pdf

Petersen, S. (2018). Dell practices what it preaches about digital transformation. eWeek 5/2/2018 (p. 4-4). Retrieved from http://www.eweek.com/enterprise-apps/dell-practices-what-it-preaches-about-digital-transformation

Reis, J., Amorim, M., Melão, N., \& Matos, P. (2018). Digital transformation: a literature review and guidelines for future research. In World Conference on Information Systems and Technologies (pp. 411-421). Cham: Springer. https://doi.org/10.1007/9783-319-77703-0_41

Schwertner, K. (2017). Digital transformation of business. Trakia Journal of Sciences, 15(1), 388-393. https://doi.org/ 10.15547/tjs.2017.s.01.065

Shallmo, D., Williams, C. A., \& Boardman, L. (2017). Digital transformation of business models - best practice, enablers and roadmap. International Journal of Innovation Management, 21(8), 1740014 (17 pages). https://doi.org/ 10.1142/S136391961740014X

Terrar, D. (2015). What is digital transformation? Retrieved from http://www.theagileelephant.com/what-is-digital-transformation/

Von Knop, J. (2016). Chemistry 4.0 challenges and solutions for the digital transformation. Croatica Chemica Acta, 89(4), 397402. https://doi.org/10.5562/cca3132

Wang, R. (2015). The elements of business architecture for digital transformation. Retrieved from https://www.constellationr.com/ research/elements-business-architecture-digital-transformation

Westerman, G., \& Bonnet, D. (2015). Revamping your business through digital transformation. MIT Sloan Management Review, 56(3), 10.

What is digital transformation? (2015). Retrieved from https://enterprisersproject.com/what-is-digital-transformation\#q1

Wood, J. M. (2007). Understanding and computing Cohen's Kappa: A Tutorial. Retrieved from: http://wpe.info/vault/wood07/Wood07.pdf

World Economic Forum. (2016). Digital Transformation of industries: In collaboration with Accenture. Retrieved from http://reports.weforum.org/digital-transformation/wp-content/blogs.dir/94/mp/files/pages/files/digital-enterprise-narrative-final-january-2016.pdf

World Economic Forum. (2018a). Digital transformation initiative. Retrieved from http://reports.weforum.org/digital-transformation/wp-content/blogs.dir/94/mp/files/pages/files/dti-executive-summary-20180510.pdf 
World Economic Forum. (2018b). Innovation with a purpose. The role of technology innovation in accelerating food systems transformation. Retrieved from http://www3.weforum.org/docs/WEF_Innovation_with_a_Purpose_VF-reduced.pdf

World Economic Forum. (2018c). Moving from experimentation to transformation. In: Collaboration with Bain \& Company. Retrieved from http://www3.weforum.org/docs/Media/47538_Digital\%20Enterprise_Moving_Experimentation_Transformation_report_2018\%20-\%20final\%20(2).pdf

Zhu, K., Kraemer, K. L., \& Xu, S. (2006). The process of innovation assimilation by firms in different countries: a technology diffusion perspective on e-business. Management Science, 52(10), 1557-1576. https://doi.org/10.1287/mnsc.1050.0487

Zysman, J., Murray, J., Feldman, S., Nielsen, N. C., \& Kushida, K. E. (2011). Services with everything: The ICT-enabled digital transformation of services. BRIE Working Paper No. 187a. https://doi.org/10.2139/ssrn.1863550 